\title{
PROPOSTA DE IMPLEMENTAÇÃO DE ESTRATÉGIAS PARA O DESENVOLVIMENTO DO MERCADO DO EMPREENDEDORISMO: ESTUDO DE CASO NA EMPRESA BAZAR DA RAYANA
}

\author{
ARTIGO ORIGINAL \\ LOBO, Juliana Parente ${ }^{1}$ \\ SILVA, Jully Maria Matos ${ }^{2}$ \\ CARVALHO, Raiana Medeiros De ${ }^{3}$ \\ ROBERTO, José Carlos Alves ${ }^{4}$
}

LOBO, Juliana Parente. Et al. Proposta de implementação de estratégias para o desenvolvimento do mercado do empreendedorismo: Estudo de caso na Empresa Bazar da Rayana. Revista Científica Multidisciplinar Núcleo do Conhecimento. Ano 05, Ed. 11, Vol. 03, pp. 29-48. Novembro de 2020. ISSN: 24480959, Link de acesso: https://www.nucleodoconhecimento.com.br/administracao/desenvolvimentodo-mercado

\section{RESUMO}

O artigo apresentado tem por finalidade analisar as estratégias adotadas no mercado do empreendedorismo, com base no estudo de caso realizado na empresa Bazar da Rayana. A pesquisa tem o propósito de demonstrar a ferramenta 5W2H como uma ferramenta técnica para o empreendedorismo, que possibilitará estratégias

\footnotetext{
${ }^{1}$ Graduanda em Administração.

2 Graduanda em Administração.

${ }^{3}$ Graduanda em Administração.

${ }^{4}$ Orientador. Mestre de Engenharia da Produção.
} 
mercadológicas para desenvolvimento do negócio e futuras parcerias comerciais. $\mathrm{O}$ estudo segue fundamentos metodológicos e possui caráter descritivo, exploratório, qualitativo e bibliográfico, como meio de obter cientificidade no que é proposto. A escolha do tema empreendimento, deu-se no diagnóstico organizacional com a aplicações de técnicas utilizadas para o levantamento de informações precisas. A pesquisa tem o intuito de analisar os aspectos que impactam a motivação e liderança no empreendedorismo. A ferramenta $5 \mathrm{~W} 2 \mathrm{H}$ contribuíra para a qualidade total dos processos, capaz de promover melhorias significativas nos resultados da organização, identificando gargalos, reduzindo despesas para melhorar o aproveitamento de materiais, e melhorias nos serviços, redução de acidentes. As melhorias apresentadas trarão satisfação dos funcionários com a realização de atividades com resultados positivos para a empresa.

Palavras-Chave: Empreendedorismo, ferramentas, técnica.

\section{INTRODUÇÃO}

O presente artigo é um estudo de caso formulado no Bazar da Rayana, que atua no seguimento de vestuário em geral. O estudo inicia-se com diagnóstico organizacional, onde aponta por meio de técnicas aplicadas com a proprietária e funcionários, que a empresa Bazar da Rayana necessita de estratégias voltadas para o empreendedorismo.

A mudança no cenário mundial tem modificado a perspectiva econômica e social. Essas mudanças trazem novas oportunidades para quem preferem ousar-se no mercado do empreendedorismo. Diante de tal inquietação cria-se o objetivo geral de "Implementar estratégias para o desenvolvimento do mercado empreendedor no Bazar da Rayana", essas estratégias vêm como oportunidade de desenvolvimento para o seguimento empresarial.

O empreendedorismo é a oportunidade de criar e planejar o desenvolvimento de uma empresa. Com o empreendedorismo o gestor estará seguro que as ferramentas adotadas serão eficientes e eficaz em cada situação, pois a empresa terá RC: 63945

Disponível em: https://www.nucleodoconhecimento.com.br/administracao/desenvolvimento-domercado 
fundamentos sólidos que consolidarão a permanência da organização por um longo período de tempo.

Com o empreendedorismo adotado pela empresa como estratégia organizacional é possível agregar melhorias que impactarão positivamente o futuro da organização. As mudanças empresariais farão que os funcionários estejam motivados em fazer parte da empresa, com isso, desempenharão com satisfação as atividades desenvolvidas por eles. E como resultado a empresa aumentará o seu rendimento.

Visando aumentar a competição no seguimento de vestuário, a empresa Bazar da Rayana terá vantagens competitivas com empresas que atuam no mesmo ramo, visto que terá toda a base essencial que qualquer empresa precisa para solidificar-se no mercado. O empreendedorismo será usado como ferramenta que apoiará a gestora como estratégia empresarial.

Para garantir que o empreendedorismo seja garantido, deve-se ter auxílio da ferramenta $5 \mathrm{~W} 2 \mathrm{H}$ como meio de alcançar o objetivo empresarial. A ferramenta $5 \mathrm{~W} 2 \mathrm{H}$ é uma técnica de ferramenta da qualidade que pode ser usada como gestão estratégica pelo gestor que terá em mãos o amparo suficiente para a tomada de decisão.

O estudo dividiu-se em várias etapas, iniciando-se com o resumo, posteriormente faz uma breve introdução do que está sendo explanado, e segue com a fundamentação teórica acerca do tema o empreendedorismo, adiante a metodologia aplicada para a elaboração do artigo, enfim apresenta-se a empresa Bazar da Rayana, para dar continuidade sucede-se com resultados e discussões, finalizado com a conclusão.

\section{FUNDAMENTAÇÃO TEÓRICA}

A fundamentação teórica apresenta importantes conceitos que fundamentam e contribuem com o tema recomendado que é empreendedorismo. Portanto as justificativas e características sobre o assunto em questão, do ponto de vista da análise, são feitas por diversos autores que abordam o assunto, além de dar suporte

Disponível em: https://www.nucleodoconhecimento.com.br/administracao/desenvolvimento-domercado 
à aplicação de modelos ou tipologias relacionados a conceitos relevantes e valores organizacionais, ambientais e pessoais.

O artigo faz uma abordagem do tema empreendedorismo, que é um assunto bastante relevante para o crescimento mercadológico e econômico no Brasil. Dornelas (2008) classifica o empreender como parte integrante e idealizadora de uma pessoa, que pode ser influenciado pelo ambiente no qual está inserido. No Brasil nos últimos anos houve uma estabilização da economia advinda da globalização, as empresas têm buscado alternativas para aumentar a competitividade, reduzindo custos para manterse no mercado.

O referencial teórico da presente pesquisa foi estruturado em tópicos que se estruturou no campo do conhecimento com as principais referências na definição do conceito e dimensões do que é proposto.

\subsection{A LIDERANÇA COMO ELEMENTO DO COMPORTAMENTO EMPREENDEDOR}

No mundo dos pequenos e grandes negócios existe a competitividade entre os concorrentes, e para ter um diferencial competitivo no ramo empresarial é necessário que o gestor tenha o espírito empreendedor como garantia de sobrevivência. Empreender e liderar requer disciplina gerencial própria, para aproveitar a oportunidade empresarial que pertence. As estratégias de liderança contam como resultado de geração de novos empregos, fornecem inovações e incentivam o crescimento econômico (RIES, 2012). Diante do exposto, constata-se que é obrigatório que o gestor tenha o conhecimento adequado e use técnicas para tornarse um empreendedor de sucesso em seu negócio

Para tornar-se um empreendedor é de suma importância que o gestor esteja disposto a assumir riscos num cenário de muitas incertezas. Os líderes são considerados fontes que assumem determinados riscos econômicos, pois a sociedades está em constante mudança de transformação e crescimento. Empreender pode ser 
considerado como uma ação criativa, corajosa e motivacional, é basicamente a realização de um determinado projeto pessoal ou organizacional que diante de desafios permanente cria-se a oportunidade (LEITE, 2012). E assim surgem pessoas com tais perfis, dispostos a iniciar um novo negócio, com liderança dinâmica que permite participação no desenvolvimento econômico.

A adaptabilidade em ambientes de oportunidades incertas pode ser instigada por meio de processos e graus de flexibilidade. Ser empreendedor é sintetizar a ação de liderar, é basicamente influenciar e conduzir pessoas nas situações em que é identificado um objetivo claro e comum a todos, buscando alcançar metas predeterminadas (VIGNOCHI; LEZANA; PAINES, 2019). A liderança, abrange processos racionais, visionários e cognitivos, desenvolvidos na mente do empreendedor, é uma competência decisiva para identificar oportunidades e empreender em ambientes de incertezas.

\subsection{MOTIVAÇÃO EMPREENDEDORA}

A palavra motivação deriva da palavra "móbil" onde significa mover, e "ção" que significa ação, no qual podemos interpretá-la como algo que estimulam as pessoas a fazer determinadas ações. De acordo com o Dicionário Aurélio, o termo motivação é o ato ou efeito de motivar, expor motivos ou causas ou, ainda, tem-se como conjuntos de fatores que determinam a conduta de indivíduo. Bozzo et al (2019), relata que desde a antiguidade, busca-se compreender o que motiva a ação do homem na sua relação com a natureza, com seu semelhante e com a sociedade. Os empreendedores são motivados por questões de realização pessoal, associado a uma ideologia no qual encontram satisfação em conquistar, como ser dono do próprio horário, ter mais tempo com a família e amigos, e ter a consciência de que o tempo é gerenciável.

A motivação modifica a relação de equilíbrio de trabalho e vida pessoal, de modo que os donos de negócios possam desfrutar de níveis mais elevados desse equilíbrio orientado ao seu próprio negócio. Para Silva, Krüger e Kazcam (2020) a motivação empreendedora divide-se em duas classes distintas, são elas: Intrínseca: relaciona- 
se ao comportamento propriamente dito, onde busca o prazer e satisfação com a atividade desenvolvida, ao qual denomina-se motivação intrínseca; Extrínseca: por sua vez relaciona-se ao alcance de algum determinado objetivo, ao recebimento de retorno ou recompensa, tratando-se de motivação extrínseca.

\subsection{ASPECTOS HISTORICOS DO EMPREENDEDORISMO}

O termo empreendedor apareceu na Idade Média, direcionado ao indivíduo que ficavam diante de grandes operações. Tal indivíduo administrava projetos, por meio de recursos disponíveis que vinham do governo.

A palavra empreendedor (entrepreuneur) foi primeiramente empregada pelos franceses no início do século XV, para nomear os homens envolvidos na coordenação de operações militares. No entanto, somente no século XVII, houve o surgimento da relação entre assumir riscos e empreendedorismo, no qual se era estabelecido um acordo entre governo e o empreendedor quanto a execução de serviço ou fornecimento de um produto (SPUDEIT et al, 2019). Nos tempos atuais, onde existem inúmeras incertezas de um empreendimento dar certo, surgem inúmeras oportunidades para a criação de uma nova empresa, basta ter planejamento e ousadia.

No Brasil, tem-se como marco do empreendedorismo a criação do Serviço Brasileiro de Apoio às Micro e Pequenas Empresas (SEBRAE) e a Sociedade Brasileira para Exportação de Software (SOFTEX), na década de 1990. A partir de tal fato, os empreendedores puderam ter direção e suporte em relação às informações sobre como dar início a uma empresa (DORNELAS, 2014). O SEBRAE auxilia os empreendedores com capacitações e consultorias para resoluções de pequenos problemas no negócio, proporcionando aos mesmos o desenvolvimento e condução de suas próprias empresas rumo ao sucesso no mercado. 


\subsubsection{A DIFERENÇA DO EMPREENDEDOR E INTRAEMPREENDEDOR}

Como um processo de inovação, transformação e mudança, pode-se considerar um processo de ousadia em assumir riscos, cujo sucesso depende exclusivamente do empreendedor e de seu próprio desempenho. Para Werlang, (2015) define o empreendedorismo como um processo relacionado com a inovação, com o objetivo de trazer descobertas positivas para si mesmo e para os outros, que estimula a geração de capitalização através de novos negócios e ajudam no desenvolvimento do país. Já o intraempreendedorismo é caracterizado por um conjunto de atitudes pessoais com o objetivo de buscar inovação e identificar, estruturar e criar oportunidades de mercado, conseguir fazer novas combinações dos recursos disponíveis na organização, melhorar algo já feito pela empresa e agregar valores as necessidades não atendidas em uma organização.

\subsubsection{EMPREENDEDORISMO POR NECESSIDADE E OPORTUNIDADE}

O empreender surge da necessidade de pessoas comuns, que desenvolvem um negócio como fuga de fatores sociais, econômicos e ambientais. Dentre esses fatores estão; o desemprego, a falta de oportunidade no mercado de trabalho e entre outras situações que levam um ser humano a buscar de melhoria de vida. Chiavenato (2007), aponta que os fatores ambientais encorajam as pessoas para os novos negócios. Os fatores são definidos como 'refugiados'. O termo refugiados faz-se distinções como: Refugiados estrangeiros, são pessoas que vem de outros países, atraídos por empregos e salários ou iniciam seu próprio negócio; Refugiados corporativos, são pessoas que não gostam de trabalhar em ambientes burocráticos das grandes e médias empresas; Refugiados dos pais, são aquelas pessoas que deixam a família para ter um negócio independente; Refugiados do lar, são pessoas que começam um pequeno negócio depois que os filhos crescem; Refugiadas feministas, são mulheres descriminadas com restrição em empresas, por serem intituladas como o sexo frágil; Refugiados sociais, são alheios a cultura, buscando atividades como empreendedores; E os Refugiados educacionais, são os que estão cansados de uma 
vida acadêmica. Essas são as inúmeras razões que fazem homens e mulheres a aventurar-se em busca de uma melhoria de condição financeira e social.

\subsubsection{PERFIL DO EMPREENDEDOR}

Para entrar no mercado do empreendedorismo o gestor dever ter traços que são indispensáveis como: ousadia, determinação e confiança, essa são as peculiaridades específicas e determinantes para o sucesso e garantia de sobrevivência corporativa. Leite (2012), afirma que empreender pode ser considerado como uma ação criativa, corajosa e motivacional, é basicamente a realização de um determinado projeto pessoal ou organizacional diante de desafios permanente e as oportunidades de risco.

O empresário de sucesso exerce algumas características de perfil que se configura como empreendedor. Segundo Chiavenato (2007), a característica do perfil empreendedor é assunto um tanto complexo, e define a existência de três características básicas dos quais identificam o ímpeto empreendedor, sendo:

- Necessidade de realização: Os empreendedores no geral, apresentam uma alta necessidade de realização em relação ao meio social. Essa característica pode ser evidente desde cedo, até mesmo na infância, onde os impulsionam para o processo de realização de um sonho ou uma meta.

- Disposição para assumir riscos: Desde o início, o empreendedor deve estar disposto a assumir variados riscos, como financeiro, familiares e principalmente os psicológicos. Pessoas com alta necessidades de realização, possuem propensões moderadas para assumir riscos, contudo a preferência do risco reflete na autoconfiança.

- Autoconfiança: Empreendedores que possuem autoconfiança, sentem que podem enfrentar os problemas que estarão por vir. Existem pesquisas que mostram que sabendo de todos os desafios, o empreendedor acredita que é possível superá-los, descartando assim possíveis crenças limitantes. 
Figura 1 - As três características básicas do empreendedor

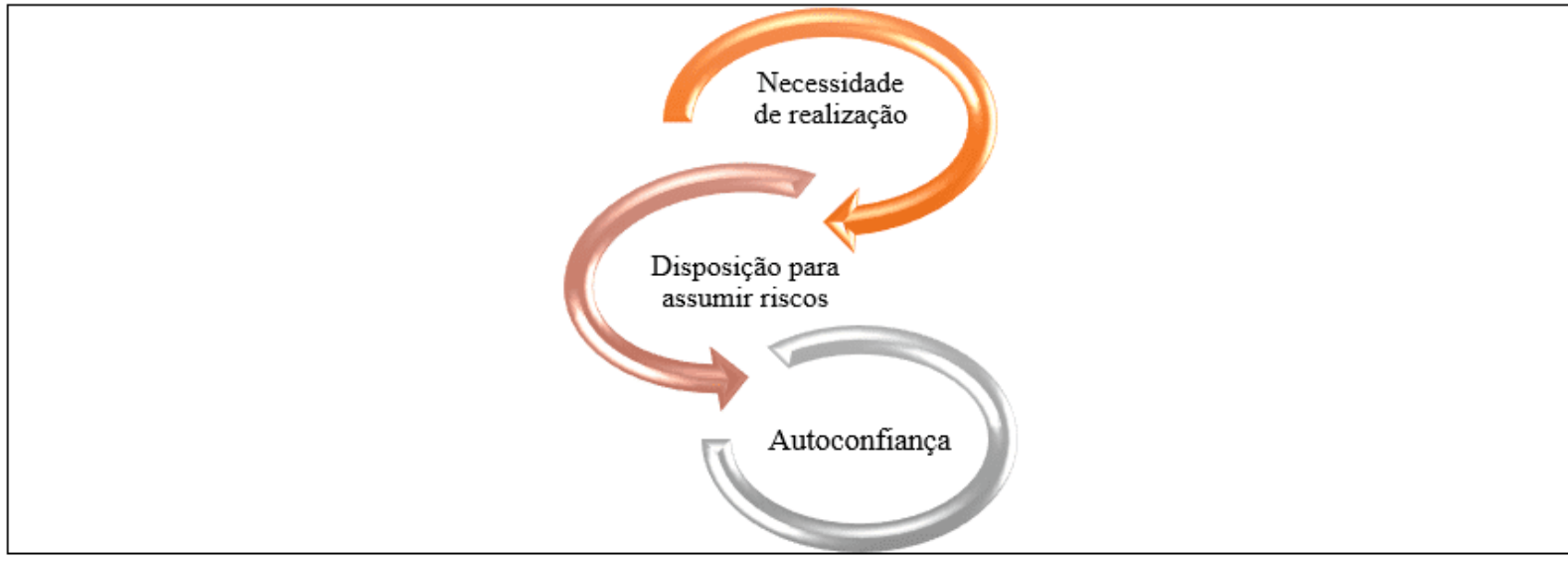

Fonte: Chiavenato (2007), adaptação dos autores, 2020.

A figura acima mostra três características que identificam um empreendedor, são elas: a necessidade de realização, disposição para assumir risco e autoconfiança, e cada particularidade impacta diretamente na vida profissional e pessoal do empreendedor. Barbosa e Costa (2015) destacam as características comportamentais dos empreendedores, que estão fortemente condicionadas com o seu próprio sucesso, onde saber gerenciar uma empresa e liderar um grupo é extremamente determinante para o sucesso organizacional em cenários de extremas incertezas e competitividade. Diante do descrito pelo autor o empreendedor deve ter liderança de equipe para conquistar o sucesso do empreendimento.

\subsection{O EMPREENDEDORISMO NO MERCADO ATUAL}

O empreendedorismo possui propriedades que favorece o crescimento econômico no país. De acordo com dados do Governo Federal, o Brasil possui entorno de 600 mil empreendimentos, por ano. Em 2019, calcula-se que um 1,5 milhão de microempreendedores tenham surgido em todo o território nacional. Nassif et al (2020) dizem que cerca de $98,5 \%$ dos aproximadamente cinco milhões de empreendimentos no Brasil, são compostos por micro e pequenas empresas (MPEs). E que a pandemia tem impactado setores da indústria, comércio e serviço. Estas oscilações do mercado e a conjuntura econômica estão expostas a riscos.

Disponível em: https://www.nucleodoconhecimento.com.br/administracao/desenvolvimento-do$\underline{\text { mercado }}$ 
Nos últimos anos, a importância dos pequenos empreendimentos no desenvolvimento social, na redução da pobreza e no crescimento econômico tem um reconhecimento significativo para o desenvolvimento do país.

Com a falta de oportunidade, falta de emprego e recursos, muitos indivíduos aventuram-se no empreendedorismo como meio de garantir a sobrevivência individual ou familiar arriscando-se a cada dia em criar oportunidades como meio de fonte de renda.

\subsection{POLÍTICAS PÚBLICAS DE APOIO AO EMPREENDEDOR}

As políticas públicas de fomento ao empreendedorismo são cruciais para o desenvolvimento econômico e social. As micro, pequenas, médias e grandes empresas tem o papel fundamental na sociedade que são: gerar empregos, crescimento econômico, diminuição das desigualdades sociais e inovação. Gomes, Alves e Fernandes (2013) afirmaram que vários autores têm falado da hipótese denominada schumpeteriana, e fazem uma analogia categórica na atividade empreendedora, no crescimento da economia, no aumento do emprego, na diminuição da desigualdade social; no desenvolvimento da cadeia produtiva das empresas multinacionais - (EMNs) e no desenvolvimento de iniciativas de sustentabilidade. No entanto novas evidências revelam que algumas empresas com o crescimento acelerado, possuem grande impacto em relação à geração de empregos e ao crescimento econômico.

\section{MATERIAIS E METÓDOS}

A metodologia é um conjunto de fases, em que o pesquisador direciona o seu projeto determinando critérios em busca de dados para embasar sua teoria inicial. Conforme Praça (2015) os métodos de pesquisa são conjuntos de técnicas adotadas para a elaboração e avaliação de entrevistas, observação, questionário e formulários, que são adotados pelo pesquisador para a realização do estudo. Este estudo consiste na descrição de todos os métodos e técnicas a serem utilizadas para execução da 
pesquisa, onde orientam-se pelo levantamento de dados a partir de um estudo de campo, correspondente à coleta de informações na empresa escolhida.

A pesquisa apresenta ferramentas metodológicas que auxiliam o estudo como meio de comprovação cientifica no que está sendo investigado.

\subsection{PROCEDIMENTOS METODOLÓGICOS}

A pesquisa apresentada é de caráter descritivo exploratório e qualitativo. A investigação procede por um estudo de caso realizado em um empreendimento voltado para o ramo de vendas.

A escolha do tema empreendedorismo foi comprovada com base em técnicas utilizadas para a coleta de informações por meio de entrevista com a proprietária e funcionários, e análise das informações apontou que o talento humano da empresa Bazar da Rayana precisa investir em treinamentos aos colaboradores como forma de motivação e liderança no empreendedorismo.

\subsubsection{QUANTO À NATUREZA}

A pesquisa é baseada em questão básica e tem por natureza a pesquisa qualitativa, que se deu por meio da análise das coletas de dados de informações, onde demonstrou a importância da liderança e motivação no mundo do empreendedorismo. Del Buono (2015) classifica a pesquisa cientifica como pesquisa básica e pesquisa aplicada. A diferença é que a pesquisa básica tem como foco de gerar conhecimento, enquanto a pesquisa aplicada a intenção de desenvolver e criar novas tecnologias palpáveis pela sociedade.

\subsubsection{QUANTO AOS FINS}

Quanto aos fins, o estudo está centrado na pesquisa exploratória com embasamento sobre o tema empreendedorismo como método de liderança e motivação, proposta para melhorar o entendimento e conhecimento a respeito do tema. Para Casarin e 
Casarin (2012, p. 43) quanto aos fins do estudo "Toda pesquisa independentemente de sua tipologia, é realizada visando atingir um objetivo".

\subsubsection{QUANTO AOS MEIOS}

Quanto aos meios utilizados para a construção do artigo, deu-se por embasamento bibliográfico em autores que abordam sobre o tem proposto, como forma de dar credibilidade ao estudo. Segundo Köche $(2015$, p. 122) a pesquisa quanto aos meios "É a que se desenvolve tentando explicar um problema, utilizando o conhecimento disponível a partir das teorias publicadas em livros ou em obras congêneres". No decorrer do artigo apresenta-se diversos autores que falam sobre 0 empreendedorismo como meio de fundamentar o que está sendo abordado.

\subsection{CARACTERÍSTICAS DA EMPRESA}

Figura 2 - Logomarca do Bazar da Rayana, 2020.

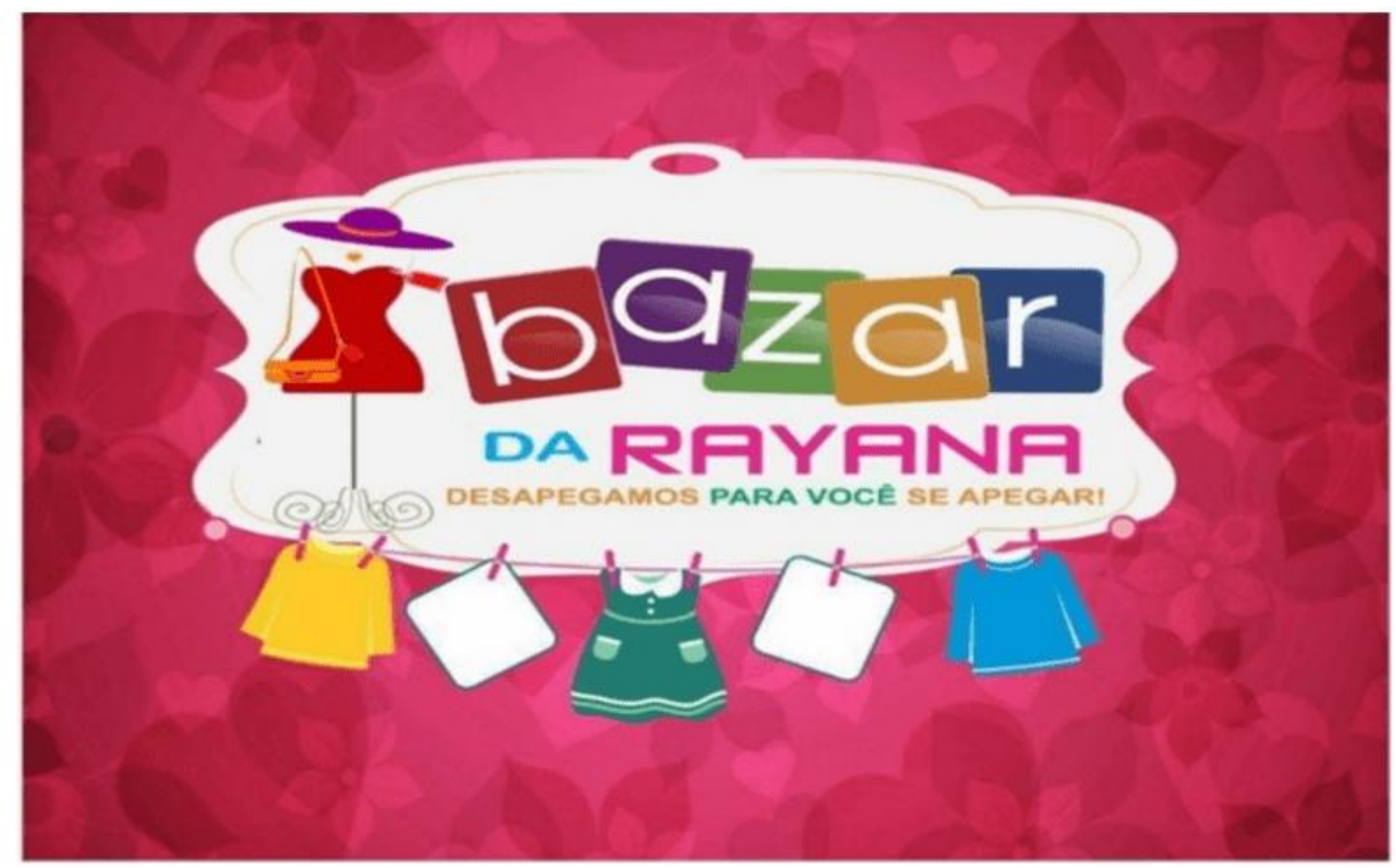

Fonte: autor.

Disponível em: https://www.nucleodoconhecimento.com.br/administracao/desenvolvimento-domercado 
O escritório do empreendimento Bazar da Rayana está localizado na Rua Beco São Lucas, № 35-1, no bairro da Compensa, zona oeste de Manaus. A Empresa foi criada no ano de 2015 como um bazar popular, iniciando suas operações com a venda de vestuários novos e usados.

Atualmente o Bazar da Rayana é considerado o maior da Cidade de Manaus, com todos os documentos necessários para o funcionamento. O Bazar da Rayana promove eventos que tem por características vender peças de baixo custo, contando com uma média de 80 a 100 participantes. Atualmente o Bazar conta com seis funcionários, que são responsáveis pela montagem de palco e delimitação dos stands. A empresa aposta fortemente no marketing comercial, em diversos meios possíveis. Os produtos apresentados para público são de roupas, sapatos, perfumaria, bijuterias, semi joias entre outras variedades com o preço de 1,99 a 70,00 reais, tornando-se um bazar acessível ao público.

\section{RESULTADOS E DISCUSSÕES}

O estudo de caso realizado no Bazar da Rayana, seguiu diretrizes técnicas como entrevista com a gestora e funcionários. Por meio da coleta de informações, detectouse que há inconformidades na empresa, e que necessita de mudanças para a melhoria no empreendimento.

\subsection{GRÁFICO DAS ÁREAS MAIS CRÍTICAS}

Com base nas informações levantadas elaborou-se o gráfico que mediu o desempenho da empresa. 
Gráfico 01 - Medição de desempenho

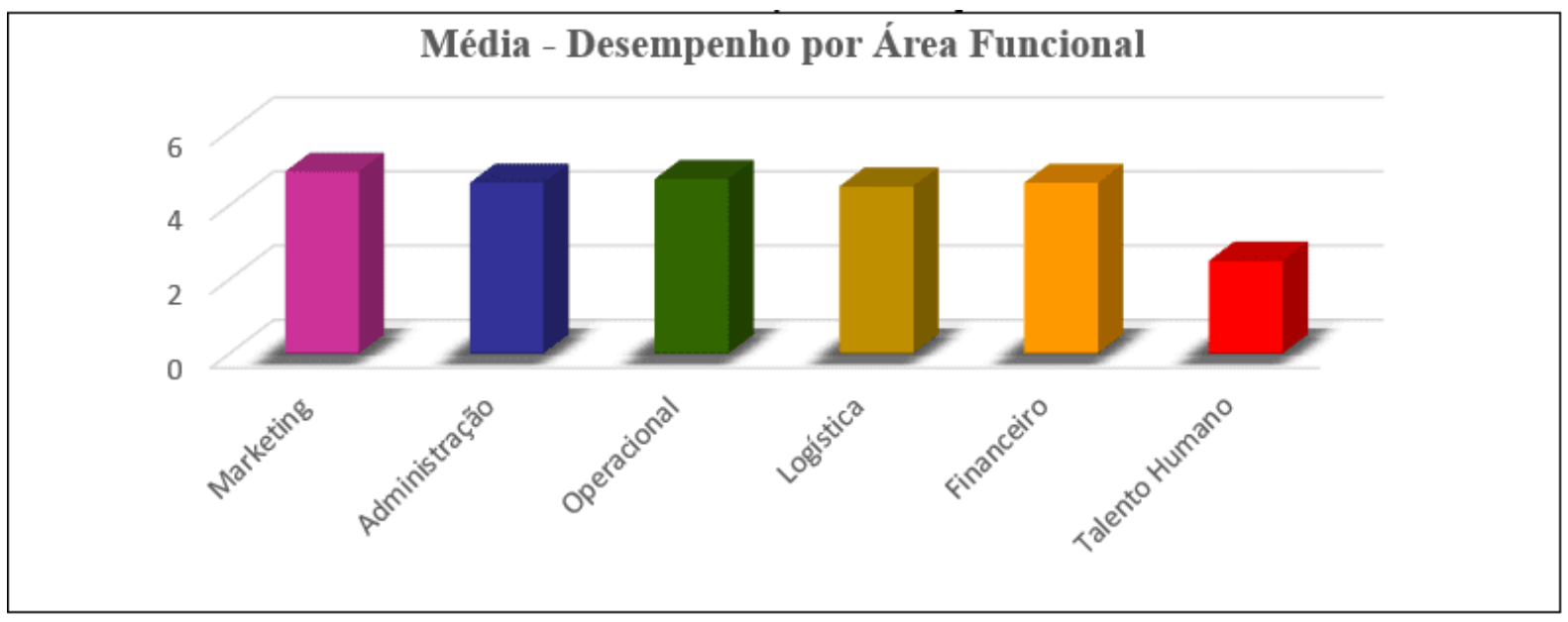

Fonte: Elaborado pelos autores, 2020.

No gráfico 1 nota-se que o empreendimento tem a área do marketing e operacional tem o maior desempenho. $E$ as áreas de administração, financeira e de logística estão com desempenho equilibrado. No entanto o talento humano ficou sendo a área mais crítica, que necessita de atenção do gestor.

Todas as propostas apresentadas tem plano de ação com planejamento e possuem fundamentos metodológicos para aplicação das técnicas necessárias como forma de melhorar o desempenho das atividades executados pelos funcionários.

\subsection{QUADRO DA ÁREA MAIS CRÍTICA}

No quadro da área mais crítica, observa-se que existem pontos a melhorar, e tais melhorias dependem da proposta de implementação de treinamento voltado aos colaboradores da empresa Bazar da Rayana, como forma de resolver a problemática demonstrada no quadro, por meio de estratégias de motivação aos funcionários com treinamentos adequados para o melhor desempenho das atividades por eles desenvolvidas. 
Quadro 01: Talento humano

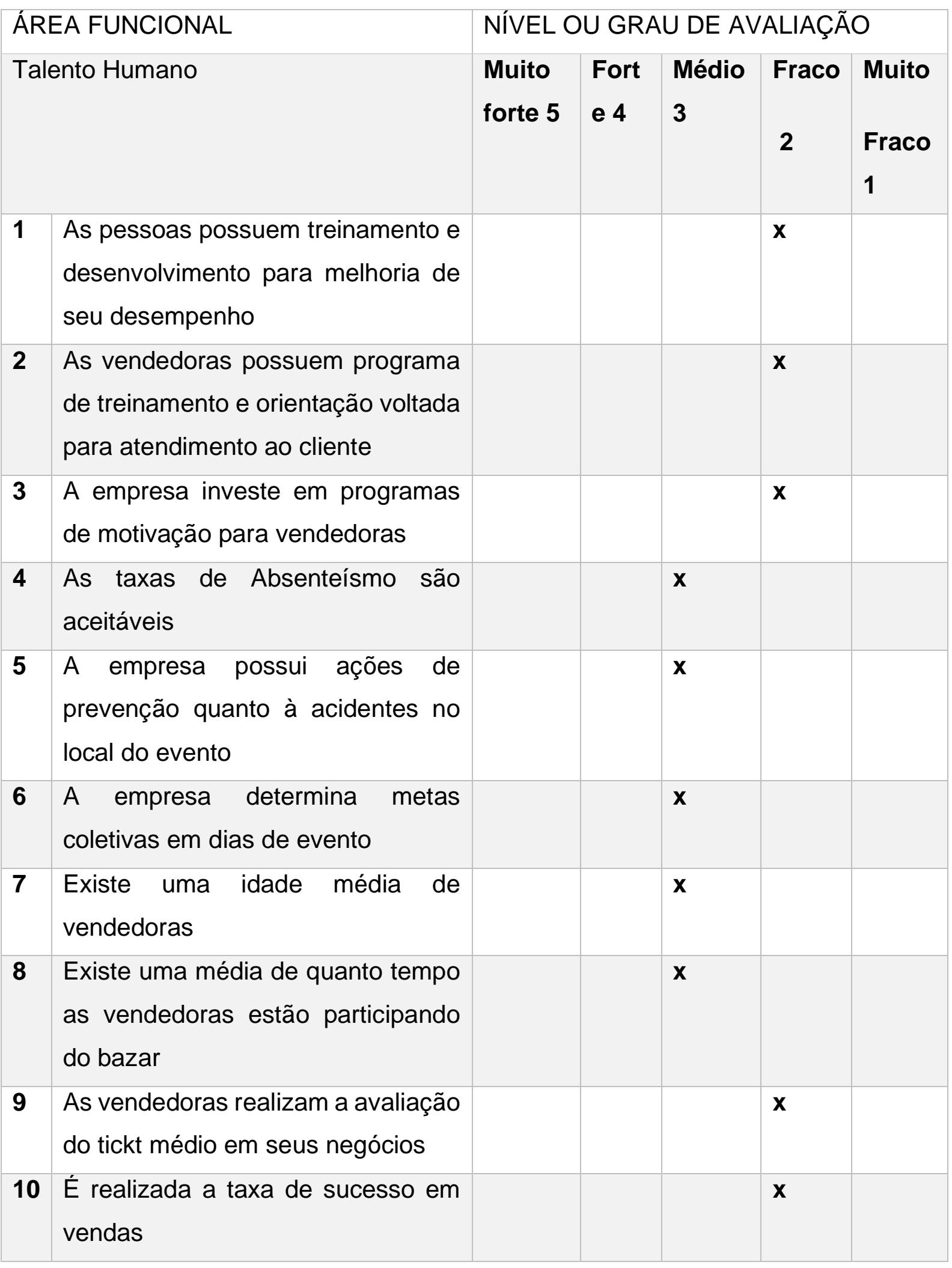

Disponível em: https://www.nucleodoconhecimento.com.br/administracao/desenvolvimento-do$\underline{\text { mercado }}$ 


\begin{tabular}{|l|l|l|l|l|l|}
\hline Total $(\Sigma)$ & 0 & 0 & 15 & 10 & 0 \\
\hline Média por grau - Por coluna & 0 & 0 & 1,5 & 1 & 0 \\
\hline Desempenho da área & 2,5 & & & & \\
\hline
\end{tabular}

Fonte: Elaborado pelos autores, 2020.

O quadro 1 aponta que o nível ou grau de avaliação realizado no Bazar da Rayana variam entre os números entre 3 e 2 , e isso demonstra que o empreendimento necessita de melhorias como forma de aperfeiçoar o desempenho da empresa. Baggio e Baggio (2014), afirmam que é necessário criar estratégias para empreender, que são motivadas pelo impulso da concretização de uma ideia, com iniciativa de buscar novos desafios com a ciência dos recursos disponíveis e dos riscos que por vezes podem vir acontecer. As melhorias no desempenho serão por meio implementação de programas de treinamento e motivação para os funcionários da empresa como forma de motivação na prestação do serviço com qualidade.

\subsection{PLANEJAMENTO DE AÇÕES}

O plano de ação é uma ferramenta ou metodologia que define ações necessárias para que se alcance objetivos frente as estratégias propostas, com conogramas de prazos e valores, podendo trazer otimização e melhorias nos processos. Polacinski (2012) descreve que a ferramenta $5 \mathrm{~W} 2 \mathrm{H}$ consiste num plano de ação para atividades préestabelecidas que precisam ser desenvolvidas de modo claro e objetivo, a fim de servir como um mapa norteador dessas atividades. $\mathrm{O}$ autor ainda discorre e destaca que a finalidade dessa ferramenta incide em responder a sete questões e organizá-las. Com a ferramenta $5 \mathrm{~W} 2 \mathrm{H}$ será possível planejar todas as ações de melhorias com o suporte técnico de qualidade.

Quadro 02: Ações interventivas. 


\begin{tabular}{|c|c|c|c|}
\hline 1 & $\begin{array}{l}\text { Criar um cronograma temático mensal dos } \\
\text { eventos. }\end{array}$ & $1 \mathrm{dia}$ & $\mathrm{R} \$ 700,00$ \\
\hline 2 & $\begin{array}{l}\text { Implementação de medidas de apoio aos } \\
\text { negócios do evento. }\end{array}$ & Permanente & $\begin{array}{l}\mathrm{R} \$ \\
1.200,00\end{array}$ \\
\hline 3 & $\begin{array}{l}\text { Enfoque em seguimentos específicos da } \\
\text { população. }\end{array}$ & $1 \mathrm{dia}$ & $\mathrm{R} \$ 100,00$ \\
\hline 4 & $\begin{array}{l}\text { Realização de eventos para a cultura } \\
\text { empreendedora. }\end{array}$ & 2 dias & $\begin{array}{l}\mathrm{R} \$ \\
1.000,00\end{array}$ \\
\hline 5 & $\begin{array}{l}\text { Implementação da ferramenta } 5 s \text { para } 0 \\
\text { gerenciamento dos eventos. }\end{array}$ & 2 dias & $\mathrm{R} \$ 500,00$ \\
\hline \multicolumn{2}{|c|}{ TOTAL } & & $\begin{array}{l}\mathbf{R} \$ \\
3.500,00\end{array}$ \\
\hline
\end{tabular}

Fonte: Elaborado pelos autores, 2020.

A solução proposta neste item desenvolveu-se diante das áreas funcionais averiguadas, que terá como fundamento a ferramenta $5 \mathrm{~W} 2 \mathrm{H}$. A técnica $5 \mathrm{~W} 2 \mathrm{H}$ é uma ferramenta da qualidade que pode ser utilizada em qualquer empresa, a fim de registrar de maneira organizada e planejada as ações efetuadas.

\subsubsection{CRIAR UM CRONOGRAMA MENSAL DE EVENTOS}

Para melhorar as atividades dentro da empresa Bazar da Rayana é fundamental que se faça um cronograma mensal dos eventos realizados de acordo com a temática de cada mês, como forma de atrair pessoas para o evento. Nesse sentido, planejar ações comemorativas em datas especiais pode ser um estímulo para as vendedoras que estão participando, e para quem vai consumir, resultando em aumento nas vendas e fluxo de pessoas.

O ideal para o cronograma é que estabeleça datas importantes, como: dia das mães, dias dos pais, dia dos namorados, festas de fim de ano, lembrando sempre também 
das causas, como o outubro rosa e novembro azul, criando relações de ganha-ganha que é a negociação na qual ninguém perde, todos ganham.

Quadro 03 - 5w2h - Cronograma mensal temático para os eventos.

\section{Cronograma mensal dos eventos}

O que? Cronograma temáticos para os eventos.

Por quê? Para estimular as vendedoras, a inovar de acordo com os temas do mês e aumentar o fluxo das pessoas no evento.

Onde? No bazar da Rayana eventos.

Quando? Sete de novembro de 2020.

Quem? Tanto para as vendedoras tanto para os clientes.

Como? Especificar uma data, causa, ou campanha importante, e criar a relação do ganha-ganha, cliente compra um determinado valor e ganha algo em prol de seu benefício.

Quanto? $R \$ 700,00$

Fonte: Elaborado pelos autores, 2020.

O cronograma de atividade proposto no estudo tem a finalidade de tornar o Bazar da Rayana um bazar competitivo, com oportunidades e inovação no mercado.

\subsubsection{IMPLEMENTAÇÃO DE MEDIDAS DE APOIO AOS NEGÓCIOS DO EVENTO}

A implementação de medidas para sustentar os eventos terão o suporte de: redes de contatos, instruções de criação de sites, softwares, aplicativos on-line de suporte para divulgações, criação de consultoria e assistência para as vendedoras que participam do bazar, motivando-as para essa entrada ao empreendedorismo e elevando a autoconfiança em empreender. As medidas de apoio ao evento serão a segurança que o gestor terá para que cada ação seja executada com qualidade, trazendo 
retornos positivos para a empresa, que saberá o quanto terá que investir e o quanto terá de retorno.

Quadro 04: 5w2h- Implementação de medidas de apoio aos negócios do evento.

Implementação de medidas de apoio aos negócios do evento

O que? Criação de medidas de apoio aos negócios do evento.

Por quê? Falta de assistências ao microempreendedor e para estimular o desenvolvimento das vendedoras e auxiliá-las nessa entrada ao empreendedorismo.

Onde? No bazar da Rayana eventos.

Quando? Primeira semana de janeiro de 2021.

Quem? Para as vendedoras iniciantes e para quem já está empreendendo.

Como? Desenvolver programas de treinamentos e orientação, como palestras, workshops, oficinas para o aprendizado das novas tecnologias e sistemas que favorece os negócios.

Quanto? $\mathrm{R} \$ 1.200,00$

Fonte: Elaborado pelos autores, 2020.

\subsubsection{ENFOQUE EM SEGUIMENTOS ESPECÍFICOS DA POPULAÇÃO}

O enfoque para os seguimentos específicos da população é o auxílio a grupos específicos, como jovens ou mulheres. Com programas e premiações que der credibilidade a grupos de microempreendedores, assim como treinamento para o desenvolvimento pessoal e profissional, assistência na identificação de oportunidades favoráveis para esses tipos de pessoas, promovendo oportunidades de crescimento e força a eles.

Quadro 05 - 5w2h- Enfoque em seguimentos específicos da população.

Enfoque em seguimentos específicos da população.

O que? Ênfase em grupos específicos da população.

Disponível em: https://www.nucleodoconhecimento.com.br/administracao/desenvolvimento-domercado 


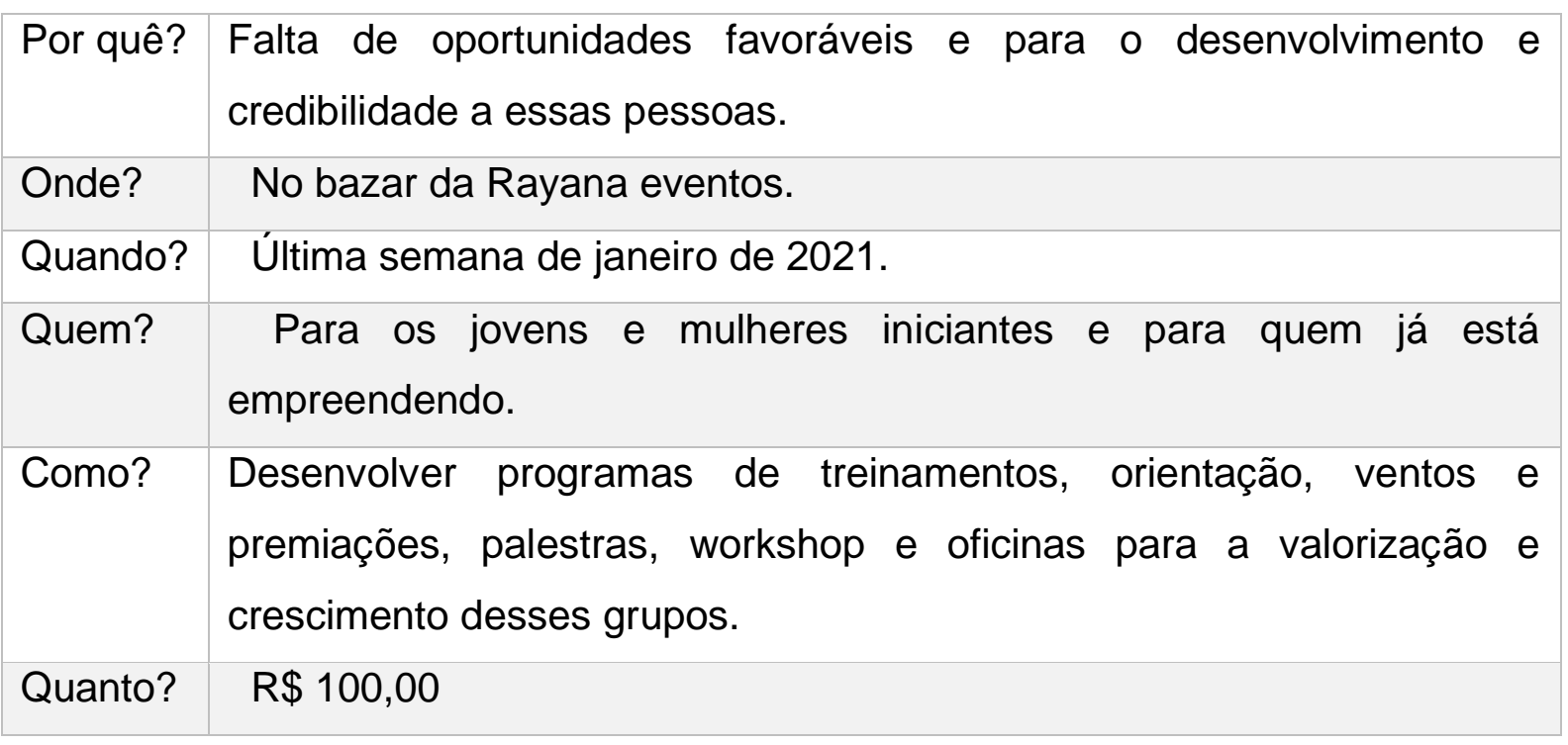

Fonte: Elaborado pelos autores, 2020.

A proposta o seguimento visa adotar estratégias de motivação que promovam o interesse no mercado do empreendedorismo, tendo como base o mercado atual e o comportamento da empresa. A estratégia é mostrar que é possível ser empreendedor onde falta a oportunidade, por meio da motivação certa é possível que outras pessoas possam arriscar-se no mundo dos negócios. Esse enfoque terá impacto positivo diretamente no público-alvo, pois muitas pessoas terão oportunidades de criar, inovar e lançar-se em um novo horizonte que promova o empreendedorismo como um conjunto de eventos estratégicos para desenvolver o negócio e parceria comerciais.

\subsubsection{REALIZAÇÃO DE EVENTOS PARA A CULTURA EMPREENDEDORA}

$\mathrm{Na}$ realização dos eventos serão necessários que a empresa dê apoio as iniciativas dos eventos culturais que elevam o crescimento do empreendedorismo, para que estejam sempre por dentro do mercado, as tendências e os temas discutidos, isso dá oportunidade para que outros futuros empreendedores de planejar as novidades e desenvolver idéias agregando conhecimento e valores ao mercado competitivo, buscando a excelência, aprendizagem e premiação que aumente a crença nos negócios. 
Quadro 06 - 5w2h- Realização de eventos para a cultura empreendedora.

\begin{tabular}{|l|l|}
\hline Realização de eventos para a cultura empreendedora \\
\hline O que? & $\begin{array}{l}\text { Realização de eventos para a cultura empreendedora. Exemplo: Feira } \\
\text { do empreendedor Sebrae, virada empreendedora (voltada para o apoio } \\
\text { às mulheres empreendedoras, Whow! Festival de Inovação. }\end{array}$ \\
\hline Por quê? & Ausência de programas, congressos e eventos. \\
\hline $\begin{array}{l}\text { Onde? } \\
\text { Quando? }\end{array}$ & No bazar da Rayana eventos. \\
\hline Quem? & Para os empreendedores iniciantes e para quem já está no mercado. \\
\hline $\begin{array}{l}\text { Como? } \\
\text { Quanto? }\end{array}$ & Participar e apoiar as ações culturais realizadas. \\
\hline
\end{tabular}

Fonte: Elaborado pelos autores, 2020.

\subsubsection{IMPLEMENTAÇÃO DA FERRAMENTA 5S PARA 0 GERENCIAMENTO DOS EVENTOS}

Nos eventos promovidos pelo Bazar da Rayana são necessários à aplicação de técnicas de ferramentas da qualidade, como meio de garantir que a atividade seja um sucesso. O uso da ferramenta $5 \mathrm{~s}$ é a forma de garantia da qualidade total na realização dos eventos.

Com a aplicação da técnica $5 \mathrm{~s}$, será possível melhorar o desempenho dos colaboradores e evitar possíveis imprevistos, assim à ferramenta auxiliará a empresa e evitará gargalos, perda de material e etc. Diante disso é possível oferecer satisfação das pessoas com o trabalho e apresentando resultados positivos.

A finalidade de implementar a ferramenta $5 \mathrm{~s}$ no gerenciamento dos eventos com planejamento fundamental que consolidarão o sucesso de cada evento criado pela empresa Bazar da Rayana. 
Quadro 06 - 5w2h- Implementação da ferramenta 5s para o gerenciamento dos eventos.

Implementação da ferramenta 5s para o gerenciamento dos eventos.

\begin{tabular}{l|l|}
\hline O que? & Ferramenta 5s \\
\hline Por quê? & Melhoria no processo de organização das pessoas envolvidas \\
\hline Onde? & No bazar da Rayana eventos. \\
\hline Quando? & Primeira semana de dezembro de 2020. \\
\hline Quem? & Para todos os envolvidos na organização \\
\hline Como? & Por meio de uma política de normas e cultura mais organizada. \\
\hline Quanto? & $\mathrm{R} \$ 500,00$
\end{tabular}

Fonte: Elaborado pelos autores, 2020.

Para resolver a questão de incertezas provocadas pela falta de técnica, a ferramenta 5s irá melhorar o desempenho das atividades dos funcionários, com a prestação de serviço de qualidade ao cliente, que ficaram satisfeitos por serem bem atendidos, enquanto os funcionários estarão motivados e satisfeitos com a prestação de serviço de qualidade.

\section{CONSIDERAÇÕES FINAIS}

Diante das incertezas que estamos vivenciando e do atual cenário econômico, muitas empresas fecharam-se as portas e muitos trabalhadores foram demitidos. Com aumento do desemprego, a informalidade vem sendo uma oportunidade para quem procura ariscar-se no empreendedorismo. Por isso, o empreendedorismo precisa driblar a realidade, transformando a necessidade em oportunidade para empreender.

A pesquisa realizada, demonstrou que o empreendedorismo faz parte das estratégias de inserção de novos indivíduos no mercado. Ou seja, o despertar do espírito empreendedor, permitindo que os mesmos promovam a sua própria inserção econômica, criando novas empresas e o desenvolvimento econômico. 
Através do estudo de caso no bazar da Rayana, observou-se que a empresa em estudo possui pontos fundamentais a serem melhorados. Nesse sentido a primeira etapa aplicada foi à ferramenta de medição de desempenho, desenhando as áreas funcionais por meio do diagnóstico organizacional, mostrando a necessidade de capacitação e desenvolvimento na área do Talento Humano, por meio da implementação de programa de treinamento e motivação.

A seguir criou-se a proposta de capacitação, melhorias e desenvolvimento nas áreas críticas mencionadas no presente trabalho. Com o quadro de ações interventivas, estipulando formas e ações adequadas para a evolução dos processos dentro dos eventos, eliminando gargalos e melhorando os processos.

O bom uso das ferramentas e métodos citados contribuíram para a qualidade total, capaz de promover melhorias significativas nos resultados da organização, como melhoria no atendimento, e padronização no gerenciamento dos eventos. Auxiliando no desenvolvimento da visão dos negócios, criando redes de parceria e ajudando no planejamento de novos empreendimentos. Visando o apoio das políticas públicas, facilitando o processo de introdução ao mercado empreendedor.

Portanto o objetivo principal foi mapear a empresa e averiguar os pontos negativos, para criar um plano de ação que possa sanar os problemas encontrados de forma geral, agregando valores e conhecimentos em ações que motivam as pessoas a empreender.

A elaboração do artigo teve por base procedimentos metodológicos e para dar credibilidade ao estudo fundamentou-se com obras de autores. Diante do exposto, recomenda-se esta pesquisa a futuros acadêmicos do Curso de Administração como material de apoio e a outros interessados no tema. 


\section{REFERÊNCIAS BIBLIOGRÁFICAS}

BAGGIO, Adelar Francisco; BAGGIO Daniel Knebel. Empreendedorismo: conceitos e definições. Rev. de Empreendedorismo, Inovação e Tecnologia: 2014. Acesso em 09 de Out de 2020.

BARBOSA, Lucas Oliveira; COSTA, Tulio Vieira Bassi. Perfil empreendedor: um estudo sobre as características do perfil empreendedor. Volta Redonda, Rio de Janeiro. 2015. Acesso em: 27 de Set de 2020.

BOZZO, Andrea Luisa; et al. Ideologia de dida e motivação empreendedora. Race, Joaçaba: 2019. Acesso em 25 de Set de 2020.

CASARIN, Helen de Castro S.; CASARIN, Samuel José. Pesquisa científica: da teoria à prática. Curitiba: InterSaberes, 2012.

CHIAVENATO, Idalberto. Empreendedorismo: dando asas ao espírito empreendedor: empreendedorismo e viabilidade de novas empresas: um guia eficiente para iniciar e tocar seu próprio negócio. $2^{\circ}$ ed. rev. e atualizada. - São Paulo: Saraiva, 2007.

DEL BUONO, Regina. O que é pesquisa básica ou científica? ABNT ou Vancouver, 2015. Acesso em: 11 Out. 2020.

DORNELAS, José Carlos A. Empreendedorismo: Transformando ideias em negócios. $3^{\circ}$ ed. Rio de Janeiro: Elsevier, 2008

. Empreendedorismo: Transformando ideias em negócios. 5ํe. Rio de Janeiro: Empreende/LTC, 2014.

GOMES, Marcos Vinicius P.; ALVES, Mario Aquino; FERNANDES, Renê José R. Políticas Públicas de Fomento ao Empreendedorismo e às Micro e Pequenas Empresas. São Paulo: Programa Gestão Pública e Cidadania, 2013. Acesso em 28 de Set de 2020. 
KÖCHE, José Carlos. Fundamentos de Metodologia Científica: teoria da ciência e iniciação à pesquisa. 34ํㅡ. ed. Petrópolis, RJ: Vozes, 2011. Acesso em 20 de setembro de 2020.

LEITE, Emanuel Ferreira. O Fenômeno do Empreendedorismo. São Paulo: ed. Saraiva, 2012.

NASSIF, Vânia Maria J. et al. Estão os empreendedores e as pequenas empresas preparadas para as adversidades contextuais? uma reflexão à luz da pandemia do Covid-19. Rev. Empreendedorismo Gestão de Pequenas Empresas. São Paulo. 2020. Acesso em 9 de Out de 2020.

POLACINSKI et al. Implantação dos 5Ss e proposição de um SGQ para uma indústria de eva-mate. João Pessoa: XXXVI Encontro Nacional de Engenharia de Produção, 2012.

PRAÇA, F. S. G. Metodologia da pesquisa científica: organização estrutural e os desafios para redigir o trabalho de conclusão. Revista Eletrônica "Diálogos Acadêmicos" 2015 Acesso em 06 de Out de 2020.

RIES, Eric. A startup enxuta: como os empreendedores atuais utilizam a inovação contínua para criar empresas extremamente bem-sucedidas. São Paulo: Lua de Papel, 2012.

SILVA, Lizana. Ilha da.; KRÜGER, Cristiane; KAZCAM, Fabiola. A relação entre motivação para aprender e intenção empreendedora em alunos dos cursos técnicos em administração e contabilidade. Rio de Janeiro, 2020. Acesso em 24 de Set de 2020.

SPUDEIT, Daniela, et al. Formação para o empreendedorismo nos cursos de bacharelado e licenciatura em biblioteconomia, ciência da informação e gestão da informação no Brasil. João Pessoa: Perspectivas em Gestão \& Conhecimento, 2019. Acesso em 08 de Out de 2020. 
VIGNOCHI, Luciano; LEZANA, Álvaro Álvaro Guillermo R.; PAINES, Patrícia de Andrade. Modelo cognitivo de liderança empreendedora. Brasília-DF, 2019. Acesso em 04 de Outubro de 2020.

WERLANG, Natalia Berger; ENGEL, Rafael. Empreendedorismo e intraempreendedorismo: uma investigação de competências empreendedoras com gestores de micro e pequenas empresas. Ágora: Revista de Divulgação Cientifica, 2015. Acesso em 03 de Outubro de 2020.

Enviado: Outubro, 2020.

Aprovado: Novembro, 2020. 